\title{
As colônias de Castrolanda, Witmarsum, Entre Rios e a agroindustrialização do campo no Paraná
}

\author{
Rene Wagner Ramos ${ }^{1}$
}

- Enviado em 05/06/2016

- Aprovado em 18/06/2016

\section{RESUMO}

O artigo analisa o processo de implantação, consolidação e do desenvolvimento atual das colônias de Castrolanda em Castro (Cooperativa Castrolanda), Witmarsum em Palmeira (Cooperativa Witmarsum) e Entre Rios em Guarapuava (Cooperativa Agrária), que deram origem as três importantes empresas paranaenses com faturamento de $\mathrm{R} \$ 4,5$ bilhões em 2015. Analisaremos a participação do governo de Bento Munhoz da Rocha, na implantação das colônias em 1951, identificando as estratégias adotadas e o discurso de justificação para o empenho do Estado nesse processo. O Projeto de Modernização do campo, tinha como premissa a transformação do modelo produtivo e sua associação ao processo industrial, como forma de agregar valor ao produto final que seria exportado.

Palavras-chaves: Colônia; Modernização; Agro-industrialização; Bento Munhoz da Rocha; Cooperativa.

\section{INTRODUÇÃO}

O processo de colonização e criação de colônias no Paraná representavam as preocupações das oligarquias tradicionais e da burguesia emergente. As colônias representavam o momento histórico e político, representado na mudança de titulares de grandes fazendas tradicionais. O processo de mudança consistia na saída de um ou de alguns membros da oligarquia por uma centena de pequenos proprietários transformados numa emergente burguesia regional ligada a agroindústria dinâmica e modernizante. Fenômeno esse que teria ressonância em vários setores da administração estadual provocando em embates políticos tanto no legislativo como no executivo (GREGORY, 2008, p. 71).

O projeto do Governo Munhoz da Rocha de Modernização do campo no Estado do Paraná, obrigaria a relação do agricultor com a terra fundamentadas em mudanças experimentadas por outras regiões do país como estabelecimento de relações capitalistas de produção, com a introdução da industrialização e a

\footnotetext{
${ }^{1}$ Pesquisador do departamento de História do Museu Paranaense (2016); mestrado em História pela UPF (2005) e doutorando em História pela UPF (2015-2019). E-mail: renewramos@uol.com.br
} 
mercantilização de todas as etapas de produção (MARTINS, 2015, p. 36). A relação capitalista foi expressa, no caso paranaense, com a criação das Cooperativas nas colônias que garantiam a compra da produção dos colonos, o beneficiamento industrial (agregando valor) e a comercialização voltado ao mercado.

No modelo agroindustrial, a grande indústria fornecedora dos equipamentos (tratores, colheitadeiras, plantadeiras, adubos químicos, fertilizantes, etc) e máquinas, transformando a modelo agrícola existente, até então, em uma agricultura capitalista, onde retira da imensa maioria do povo do campo e o domínio sobre o que produzir, para quem vender, quando vender e o por quanto vender, ou seja, a completa a separação entre a agricultura e a indústria rural doméstica, cujas raízes - fiação e tecelagem - ela arranca. Portanto, é só ela que conquista para o capital industrial todo o mercado interno. (MARX, 1996, p. 368).

O modelo de produção voltado ao mercado exportador com alta produtividade, teve como escopo uma industrialização de parte da produção e venda ao mercado externo (soja, trigo, milho e leite), esse modelo foi assim adotado no projeto. Esse modelo adotado normalmente em grandes propriedades, acabou em êxito, mas não sem problemas que explicitaremos adiante. Apesar dos colonos contarem com propriedades médias de 40 hectares, caracterizando minifúndio, onde normalmente adota-se a prática de diversificação agropecuária. Para que mesmo em minifúndios prevalecessem a lógica do mercado monocultor, exportador e produção em larga escala, implantaram-se nas colônias o sistema cooperativo que atrelava o colono ao interesse do mercado. Que exigia assim, um modelo de monocultura (trigo, soja, cevada ou leite) como forma de ganhar escala de produção para o processo da agro-industrialização, pois foram instaladas plantas industriais nas colônias como forma de agregar valor ao produto.

O sistema capitalista mostra-se incompatível com o modelo comunitário de produção dos caboclos tal comuns presentes nas regiões coloniais como explica Bourdieu (2007, p. 35) " a estrutura temporal do trabalho agrícola, atividade sazonal intrinsicamente rebelde ao cálculo e a racionalização, a dispersão espacial da população que dificulta as trocas econômicas e simbólicas. ”

As Cooperativas recebiam grandes financiamentos subsidiados pelo governo Federal e por meio do Banco do Brasil e Governo Federal da Alemanha, que repassavam aos colonos, em forma empréstimos a juros mais baixos que o praticado no mercado financeiro. Forneciam os insumos, sementes e aluguel de maquinas agrícolas. Portanto, o sistema conduziu o colono a uma espécie de dependência ficando subordinado ao interesse do sistema cooperativo. Evidente que essa lógica garantia um melhor controle da produção, acompanhamento técnico e a produção em larga escala. O sucesso de todas as etapas de produção permitiria ao colono o acesso à distribuição de lucros, já que era sócio da cooperativa. Era o novo mundo chegando definitivamente o campo no Paraná (ELFES, 1973, p. 92-93). 
Evidente que qualquer mudança na estrutura arcaica do mundo rural, marcada pelo latifúndio, baixa produtividade e pelo conflito social, onde a maioria dos agricultores brasileiros não tinham acesso a educação formal, transformando-se em uma mão-de-obra de baixa qualificação, analfabeta e facilmente substituível ficando totalmente na dependência do grande proprietário, era percebida como obra para agricultores de fora do país como afirmou Altiva Balhana, na obra Estrutura dos Campos Gerais (1968, p.44) "As autoridades alimentavam esperança de que o sistema agrícola dissociado da criação, que caracterizava a estrutura agrária paranaense, fosse modificada pelos imigrantes europeus portadores de outra tradição rural"

A região das colônias no sentido Campos Gerais e Centro-sul, ficou conhecida dentro da historiografia paranaense como Paraná tradicional. Pois a sua colonização mais antiga foi marcada pela produção do mate e do gado, com intensa atuação do tropeirismo de gado e de porcos. Trata-se de uma região marcada pelas grandes fazendas, onde ocorriam as invernadas do gado e dos porcos, portanto marcada politicamente pelo domínio dos grandes latifundiários na política regional com influência estadual (RAMOS, 2015, p. 2).

Foi no século XX que as áreas de campos passaram a ser destinadas a produção de grãos, principalmente a soja, além da criação de pastagens específicas para a produção leiteira. Pois, como afirmou Brasil Machado na obra Estrutura dos Campos Gerais (1968, p. 47) "no correr das primeiras décadas do século XX, a produção das fazendas diminuía constantemente, empobrecendo os fazendeiros. O Governo do Estado procurava deter essa decadência. As fazendas se despovoavam". A estratégia do governo foi de incentivar a formação de colônias, como uma espécie de laboratórios de desenvolvimento de práticas agropecuárias incomum entre nossos agricultores de então. Entre as quais a forte mecanização do processo do preparo da terra a colheita, correção química dos solos, sementes selecionadas e a produção e distribuição atrelada ao sistema agroindustrial.

O governador Munhoz da Rocha, acreditava que o projeto somente poderia prosperar se o mesmo fosse executado por agricultores e pecuaristas especializados dentro desse modelo de produção. Como incentivador desta modalidade de colonização, teorizava que somente a mão de obra europeia especializada estaria preparada para introduzir esse modelo produtivo agroexportador, no caso os alemães (Entre Rios), holandeses (Castrolanda) e Russos-Alemães Menonitas (Witmarsum) que se estabeleceram nas novas colônias em 1951 em detrimento dos agricultores locais praticantes de uma agricultura voltada a subsistência (ELFES, 1971, p. 6).

Esse cenário de imigração para o Brasil foi analisado em Gregory $(2008$, p. 47) 
O capitalismo crescente, na Europa, além de abalar as estruturas antigas, de provocar o êxodo de milhões de camponeses e de causar "feridas" sociais, afetava valores, crenças, concepções de vida. Aos camponeses expulsos do campo restava buscar trabalho nas indústrias e, enquanto massa operária, eram impelidos a abandonar uma vida, uma mentalidade e uma religião de cunho agrário. Diante disto, eles resistiram e restava, em muitos casos, a opção pela migração

Outro fator de atração da migração para o país foi a disponibilidade de terras para serem adquiridas no Brasil, que garantiria a condição de proprietário permitindo ao imigrante europeu uma possibilidade de uma herança aos seus filhos, algo impossível em sua terra natal como explica Gregory (2008, p.52)

Fica claro que a pequena propriedade nas regiões coloniais do Sul do Brasil é uma herança do imigrante europeu e que sua migração e de seus descendentes aconteceu por causa da possibilidade de ser proprietário e de garantir aos filhos a condição de proprietários de terra. Essa sua característica foi usada pelo Estado e pelo poder privado para a solução provisória de seus problemas advindos das contradições da estrutura econômica do Brasil. Mas, se a pequena propriedade no Brasil é uma herança do imigrante europeu, é, também, uma permissão do latifúndio. É importante ressaltar o caráter de condução, de controle, de direcionamento ao processo migratório se impunham, restando a atuação no sentido de os desdobramentos fossem favoráveis aos interesses das elites.

As áreas colonizadas caracterizam-se pela segurança quanto a titulação e pela "limpeza que significa que a área estaria livre de intrusos e de eventuais posseiros que viessem criar empecilhos à posse e a titulação tranquilas dos proprietários" (GREGORY, 2008, p. 68) como explica Gregory (2008, p. 69)

\footnotetext{
“Outras empresas, também atuaram no projeto de exploração de madeira e de colonização. Houve um intenso processo de colonização e de ocupação de terras florestais do Estado do Paraná, [...] onde empresas colonizadoras e as madeireiras vislumbravam novas possibilidades de investimento em negócios madeireiros".
}

A imigração dos anos 50, do século XX, representou uma nova fase do processo imigratório pois os grupos que chegaram ao Estado, estavam organizados em movimentos planejados, assistidos por entidades internacionais e nacionais, além do próprio Estado Federal e Estadual. A fixação desses grupos foi dirigida e financiada, diferente da imigração pioneira no século anterior, as condições para alcançar o êxito eram melhores. (WACHOWICZ, 2001, p. 156) 
O próprio Munhoz da Rocha ex-governador no prefácio do livro Suábios do Paraná (ELFES, 1971, p. 5) explicita a opção por incentivar a criação de colônias " Quando governador do Paraná estimulei a implantação de três núcleos colônias em 1951, em moldes que garantiram seu completo êxito. São eles Castrolanda, Witmarsum e Entre Rios, respectivamente nos municípios de Castro, Palmeira e Guarapuava". Rocha justifica o motivo em adotar a opção pelos imigrantes europeus nas novas áreas coloniais, seria a implantação da produção em larga escala do "trigo" em terras paranaenses, devido a dependência brasileira do produto, e que somente agricultores europeus, acostumados com o cultivo conseguiriam êxito, além disso o objetivo era também a de criar uma bacia leiteira atrelada a agro- industrialização como forma de agregar valor a produção do leite.

O governo de Munhoz da Rocha dentro da perspectiva da modernização no campo do Paraná, criou a Colônia de imigrantes Holandeses de Castro com objetivo de melhoraria da pecuária leiteira e na agricultura, além do investimento no sistema Cooperativo, assim como a de Alemães Menonitas em Witmarsum com objetivos similares.

O plano de desenvolvimento de uma agropecuária industrial associada a criação de uma bacia leiteira especializada em raças bovinas holandesas, de alta produtividade por animal, associado a industrialização de produtos derivados do leite, especialidade que seria desenvolvida pela cooperativa a Castrolanda, controlada pelos imigrantes holandeses no município de Castro.

A respeito dos projetos coloniais Bento Munhoz da Rocha afirmou que

A valorização dos Campos Gerais sempre me preocupou tanto como político quanto como professor universitário e, portanto, como estudioso de nossos problemas regionais. A valorização implicaria na implantação de pastagens artificiais em substituição aos campos nativos de pequena produtividade, com a implicação de tentar transformar a criação extensiva em intensiva, apropriando-se da terra, um rendimento mais compatível com seu valor. (Experimentação de gramíneas e leguminosas forrageiras, resistentes ao clima, em Vila Velha). A novidade de Entre Rios foi a grande lavoura de trigo e arroz em campos limpos. Essa experiência foi longamente preparada, desde muitos anos, na estação experimental do Ministério da Agricultura, em Ponta Grossa, com a organização do projeto de plantio de trigo nos campos do planalto. Guarapuava foi escolhida por seu clima mais favorável ao trabalho europeu e por sua topografia, permitindo a lavoura mecanizada, em grande escala, sem necessidade do dispendioso destacamento. Resultados entraram pelos olhos de todos, foram testemunhados por todos, e cujo exemplo foi e está sendo imitado pelos proprietários vizinhos de Entre Rios e de outros municípios. É a grande significação de Entre Rios. Seu exemplo e a imitação de seu exemplo. Resultado: Guarapuava é hoje o município maior produtor de trigo em todo o Brasil. (ELFES, 1971, p. 6) 
Conhecidos como Suábios esses alemães fundaram a Cooperativa Agrária Mista de Entre Rios entre Guarapuava e Pinhão, que se transformou em uma das maiores do Paraná. Incentivando o plantio do trigo, soja, milho e cevada, além de outras atividades agroindustriais. As ações da cooperativa promoveram uma mudança da paisagem dos campos do Pinhão, com a transformação de áreas de pastagem e matas degradadas pelo avanço das madeireiras em gigantescas plantações de trigo e soja, além de outros grãos.

A entrada desse novo cenário de produção em larga escala e a mecanização do solo voltados a exportação acabou interferindo na paisagem geográfica dos campos, pois conforme a produção foi aumentando mais áreas eram destinadas a esse modelo. As áreas limpas pela produção madeireira e pecuária foram as primeiras a serem conquistadas. Quando faltavam novas áreas a expansão desta frente se estabelece nas terras agricultáveis dos faxinais controladas pelos caboclos faxinalenses, que em sua maioria não possuíam o título de propriedade da terra, facilitando a Cooperativa a compra da posse em parceria com a indústria madeireira.

O apoio decisivo da política estadual de modernização da agricultura no Estado do Paraná, ficou latente nos incentivos de financiamento de maquinas agrícolas para os cooperados das colônias de Castrolanda, Witmarsum e Entre Rios essa última no município de Guarapuava, objeto desta pesquisa. As imagens das fotos dos maquinários agrícolas em pleno funcionamento, em 1952, quando da visita do governador Bento Munhoz da Rocha, demonstram o apoio governamental em contraste com a situação dos agricultores locais que praticavam uma agricultura de subsistência.

A Colônia de Witmarsum, apresentam características marcantes do sistema capitalista, a posse individual das terras, a propriedade dos meios de produção, a busca pelo lucro, caracterizada pela produção além da subsistência, a utilização de mão-de-obra assalariada estranhos a comunidade.

\section{A COLÔNIA WITMARSUM E O PROCESSO DE OCUPAÇÃO TERRITORIAL}

A colônia Witmarsum, no município de Palmeira, em 1951, teve sua origem num movimento espontâneo dos próprios imigrantes que se encontravam assentados em Santa Catarina, e que começaram a buscar nova área para implantarem a colônia devido as dificuldades apresentadas em terras catarinenses. A formação da colônia esteve ligada a colonização holandesa nos Campos Gerais, pois seu êxito apresentava-se como modelo e um caminho a seguir. Portanto, a fundação da colônia Witmarsum ocorreu num momento em que as áreas de campo estão em fase de recuperação e da formação de colônias de tipo capitalista com base no sistema cooperativo, considerado pelo governo paranaense essencial para seu sucesso (BALHANA, 1968, p. 55). 
É de suma importância ressaltarmos que, esse grupo étnico tem sua origem com aculturação de várias regiões da Europa entre elas a Rússia. Porém fica claro nos depoimentos dos sujeitos desta colônia que Witmarsum se coloca como de descendentes alemães, tendo em vista que o idioma falado no interior das famílias e na escola da colônia é o alemão oficial e moderno. A escola é vista como central para essa comunidade na formação do cidadão da colônia e salientarmos que, sempre ao fundarem uma nova colônia, esse grupo já projetava uma escola (EIDAM, 2014, p.70)

Esse grupo de imigrantes teve sua origem em movimento imigratório em 1930, com cerca de 1200 Menonitas que chegaram ao país, estabelecendo-se em terras catarinenses. O grupo inicialmente contava com 5000 pessoas, que fugiram da Rússia em 1929 com ajuda do governo Alemão. O desejo era de imigrar todos para o Canadá, mas como receberam somente a permissão para 1000 pessoas, o restante do grupo acabou dividindo-se entre o Paraguai e o Brasil. Foi uma imigração organizada pela Companhia Hanseática de Colonização, que dispunha de terras catarinenses, daí seu primeiro deslocamento. (BALHANA, 1968, p. 56)

A colonização em terras brasileiras e paraguaias contou com apoio financeiro de várias instituições, como a Cruz Vermelha Germânica, organizações Menonitas da Holanda e do próprio governo Alemão, pelo apoio do presidente Hindenburg aos Menonitas refugiados. Chegaram primeiramente no país em Blumenau e Ibirama em Santa Catarina, de onde foram conduzidos ao vale acidentado do rio Krauel. As dificuldades de acesso com terras cobertas por florestas subtropicais e o terreno inclinado impedia o uso de maquinas agrícolas, ficando obrigados a uma agricultura à base da enxada e produção da mandioca. A dificuldade de transporte desta mercadoria levava a perdas e encarecimento do frete, levando muitas famílias a desistirem das terras e migrarem para o Canadá.

Foi entre 1949-1950 que se deu início ao processo de transferência desta comunidade para o Paraná, que interessado em desenvolver a triticultura, o governo do Paraná incentivou e facilitou a compra das áreas de Campos no município de Palmeira, as margens da rodovia PR-376, favorecendo e resolvendo a questão do transporte. A escolha dos campos gerais baseou-se na experiência exitosa da colônia Holandesa de Carambeí na mesma região.

A escolha pelos Menonitas teve ligação com sua religião, pois como eram profundamente cristãos, a vida em comunidade e a solidariedade eram comuns, facilitando a introdução do sistema cooperativo. Pois como cristãos defendiam o bem-estar comum, mas eram contrários ao comunismo ateísta. "Dentro da estrutura nacional, ou seja, da sociedade global, a comunidade não tem tendências socializantes, muito pelo contrário, a interação da comunidade com a sociedade global, tem como canais a sua Cooperativa e a sua Igreja" (WESTPHALEM, 1968, p. 111). 
Formavam uma sociedade capitalista com a propriedade particular dos meios de produção, a busca pelo lucro individual, livre iniciativa privada e mantinham empregados assalariados. Outra característica fundamental dos Menonitas para o sucesso do empreendimento colonial foi a noção da importância da educação escolar dessa comunidade. Em 1953, fundaram a primeira escola, não tinham o hábito de esperar a ajuda do estado na educação formal. Com esse apego a educação permitiriam serem pioneiros em técnicas modernas na agropecuária, transformando-os em agricultores profissionais na aplicação de avançados progressos técnicos na agricultura (WESTPHALEM, 1968, p. 111).

A venda dos patrimônios agrícolas em Santa Catarina e também com a grande oferta de produtos causaram um grande prejuízo a comunidade com a queda dos preços- Foi necessário recorrer as comunidades irmãs dos Estados Unidos da América que emprestaram a longo prazo U\$ 35.000,00 o equivalente atual R\$ 123.550,00. Do governo Munhoz da Rocha promotor do deslocamento ao estado, receberam isenção de impostos e ajuda política para à transferência dos colonos, intermediando junto ao governo Catarinense para que não obstaculizassem a saída do grupo. A mudança ocorreu para Witmarsum até o ano de 1952, aproximadamente 150 famílias, sendo cerca de 140 agricultores (120 famílias vieram de SC e as demais do Paraguai) os demais empregados e líderes da cooperativa e da comunidade (ELFES, 1973, p. 74).

A colônia foi estruturada em cinco aldeias que por tradição Russa-Menonita, não receberam nomes apenas numeração de 01 a 05 . Os lotes variavam de 30 a 50 hectares, sendo que as colônias de 01 a 4 eram habitadas e a colônia 5 foi destinada a expansão colonial. Na antiga sede da fazenda foram instaladas as instituições de utilidade comuns, como armazéns, igreja, depósitos, moinho, fábrica de lacticínios, usina de pasteurização, escritórios da administração, salão de reuniões, de eventos sociais, hospital e escola. Toda essa estrutura ficava ao centro rodeada pelas colônias que facilitava o deslocamento das pessoas e facilitava o transporte.

Inicialmente dedicaram-se a triticultura, recorreram a experiência e a técnica da colônia holandesa de Carambeí, a qual se associaram para dedicarem-se a criação de gado leiteiro, adquirindo rebanho importado em Castrolanda. Instalaram uma usina de leite pasteurizado em 1964. Também produziram melancia no início da colonização e ocupação. Com a melhoria das condições de transporte à Curitiba, especializaram-se na criação e na produção industrial do leite e seus derivados, explorando a agricultura para produção de forragens (ELFES, 1973, p. 75).

$\mathrm{Na}$ chegada os colonos trouxeram alguns bens móveis, equipamentos agrícolas e algumas cabeças de gado. Algumas famílias trouxeram suas casas de madeira desmontadas para montá-las na nova colônia. No início tinham apenas a estrutura da fazenda, tinham estábulos e a casa principal da fazenda onde atualmente funciona o Museu. 
Com passar dos anos a Colônia foi se especializando na produção de leite e seus derivados, atingindo em 2015, o faturamento de $\mathrm{R} \$ 100.000 .000,00$ (cem milhões de reais), para a distribuições de lucros a pouco mais 100 famílias associadas.

Evidente que existem problemas ao desenvolvimento das colônias e que são de duas ordens: a distribuição dos lotes estreitos e longos o que encarece a mecanização e o trabalho de curvas de nível e principalmente a falta de reserva territorial para os filhos, a colônia n. 5 será insuficiente para as necessidades de expansão.

Existem na colônia três correntes Menonitas: A Igreja Menonita (Mennonitengemeinde); A Igreja Menonita Evangélica Livre (Freie Evangelische Mennonitengeinde) e A Igreja Irmãos Menonitas (Mennoniten Bruedergemeinde). A vida religiosa e social faz parte do cotidiano sendo que elas se confundem, a Igreja é sem dúvida o alicerce para a união da comunidade. Procuram preservar suas características étnicas as quais se diferenciavam, com o objetivo de manter sua cultura, buscam a vida rural como forma de fugir da vida urbana mais global e secular (EWERT, KARAS e LAMB, 2013, p. 70).

Apesar das diferentes formas e culto, o mesmo não interfere no cotidiano. Mas é no apoio a educação que esse grupo de destaca no meio rural brasileiro. Todas as crianças e adolescentes estão nas escolas e grande parte fazem curso superior inclusive com pós-graduação fora do País. Valoriza-se muito a educação sendo essa um grande diferencial, sendo que essa característica promove um elevado nível cultural dentro da comunidade e fora dela, que acaba refletindo na produtividade, pois muitos fazem cursos relacionados ao campo administração, economia, agronomia, veterinária, zootecnia e outros elevando a qualidade e produtividade econômica. Há ainda aqueles jovens que fazem carreira fora da colônia sem perderem os vínculos. Uma característica Menonita é a intensa solidariedade entre os seus membros (ELFES, 1973, p. $81)$.

\section{COLÔNIA DE ENTRE RIOS A PRESENÇA ALEMÃ NO CENTRO SUL DO PARANA}

O projeto de criar uma colônia para os Suábios no Brasil, teve a direção da organização "Ajuda Suíça à Europa", que havia criado uma comissão de trabalho para elaboração de um projeto de colonização. A comissão nomeou Janos Vayda, representante da Caritas suíça na América do Sul, com sede na cidade do Rio de Janeiro, como negociador junto as autoridades brasileiras. Outras organizações também contribuíram como; 'Sociedade São Rafael", de Hamburgo, na Alemanha, a "Secretaria para Indústria, Artesanato e Trabalho (BIGA)", de Berna na Suíça, a "Organização para Alimentos e Agricultura (Food and Agriculture 
Organisation - FAO)", de Washigton, Estados Unidos, a IRO, o "Comitê Internacional da Cruz Vermelha" e "Secretaria de Trabalho Internacional" (Bureau Internacional du Travail - BIT)", de Genebra, Suíça (STEIN, 2012, p. 322).

Quando chegou ao seu conhecimento as notícias que imigrantes alemães buscavam áreas para se estabelecerem no pais, envia-se como emissário o secretário de Agricultura do Estado, Francisco Peixoto Lacerda Werneck, ex-prefeito de Guarapuava, para negociar a vinda do grupo de imigrantes ao Paraná (STEIN, 2012, p. 321).

\begin{abstract}
Lacerda Werneck mostrou, por meio de um mapa, áreas no município de Clevelândia, localizada no sul do Paraná. Que foi rejeitada pelo grupo em função da distância da linha férrea. Diante da recusa, Werneck indicou uma área situada na região dos Campos Gerais, no município de Ponta Grossa. O local foi recusado em função da pequena profundidade e da alta acidez do solo. O mesmo ocorreu em uma área de Goioxim, próximo a Guarapuava. Como última tentativa, Werneck indicou uma área que estava à venda, a Fazenda Sobrado, localizada em Guarapuava. Após atravessarem em perigosa balsa o Rio Jordão, penetraram nos campos de Entre Rios e ficaram deslembrados com a planície, a extensão dos campos, a vestimenta dos campos nativos. Coletaram vinte amostras de terra - examinaram o $\mathrm{pH}$ e decidiram volta a Curitiba. Na manhã seguinte traziam um ultimatum transmitido em Entre Rios se possível fosse - outra localização, não aceitariam face às condições magníficas que os campos de entre Rios apresentavam. (STEIN, 2012, p. 321)
\end{abstract}

O governo Federal numa demonstração de apreço pelo projeto publica um decreto em 15 de janeiro de 1951, permitindo ao Banco do Brasil o financiamento do projeto de Colonização como explica Elfes (1973, p. 85) “com fundos oriundos de ágios sobre importações especiais da Suíça. Procurava-se combinar o interesse do Brasil na imigração de agricultores e industriais suíços. Era prevista para a instalação da colônia, a arrecadação de francos suíços 6.500.000,00, equivalentes a atualmente R $\$ 24.500 .000,00 ”$, ainda o governo suíço bancou a transporte ao nosso país.

Conhecidos como Suábios esses alemães fundaram a Cooperativa Agrária Mista de Entre Rios, entre Guarapuava e o Pinhão, que se transformou em uma das maiores do Paraná. Incentivando o plantio do trigo, soja, milho e cevada, além de outras atividades agroindustriais. As ações da cooperativa promoveram uma mudança da paisagem dos campos do Pinhão com a transformação de áreas de pastagem e matas degradadas pelo avanço das madeireiras em gigantescas plantações de trigo e soja, além de outros grãos.

Para trazer o projeto de colonização ao Paraná, o governador Munhoz da Rocha, envia uma carta em 09 de abril de 1951 a organização responsável pelo empreendimento "Ajuda Suíça à Europa” em sua sede brasileira no Rio de Janeiro. No documento apresentam-se várias vantagens sobre a instalação do Estado, e 
assume vários compromissos com o empreendimento. Justifica-se sua posição em face do Paraná, apresentar outras colônias alemãs de sucesso, que segundo o governo contribuíram para o desenvolvimento da agricultura e da indústria, e como acadêmico o Governador anexa à carta um estudo que demonstrava a viabilidade da instalação da colônia no município de Guarapuava. Na carta assume os seguintes compromissos pelo Estado do Paraná:

1.Trabalhos de medição e loteamento da área a ser colonizada, às expensas da Secretaria do Estado;

2. Construção da estrada de comunicação entre Guarapuava e a nova colônia;

3. Transporte dos colonos e de seus pertences desde o porto até a área a ser ocupada;

4. Mediação de professores brasileiros conhecedores da língua alemã e de um médico;

5. Financiamento do custo de vida para o grupo pioneiro durante um determinado período;

6. Acomodação, por tempo limitado, do grupo pioneiro, na cidade de Guarapuava;

7. Fornecimento de sementes e mudas, 100 porcos de criação, inclusive 50 varões, 50 vacas holandesas e dois touros, bem como 1.000 dúzias de ovos de galinhas de raça para chocar, além de remédios para a defesa animal (ELFES, 1973, p.85).

Esse apoio irrestrito dos governos municipal, estadual e federal facilitou a rapidez do processo de desapropriação das terras produzindo um conflito com os antigos proprietários como afirma Sebastião Meira Martins em sua obra Os Pioneiros do vale de Entre Rios 1818 - 1951 (1992, p. 11), pois quem não vendessem as terras segundo o "Prefeito de Guarapuava Lacerda Werneck, afirmou que o governo iria expropriar as terras daqueles que não efetuassem a venda destas Cooperativa Agrária”.

A colônia foi estruturada em cinco aldeias distantes entre 4 e $5 \mathrm{Km}$. A principal era a aldeia Vitória onde encontrava-se a sede da cooperativa Central Agrária a escola e um Hospital. Seguiu-se as aldeias Jordãozinho, Cachoeira, Socorro e Samambaia.

Até março de 1952 haviam desembarcado nas novas terras 500 famílias, das quais 323 de agricultores e os demais artesãos e operários, além das famílias dos líderes. A repartição das terras foi projetado e realizado da seguinte forma: Por família - 0,5 hectares na aldeia para a residência, edifícios de exploração econômica, pomar e estábulos; 1,0 hectare na periferia das aldeias destinado a pastagem; 15 hectares de campo limpo; 4,0 hectares de mata de Araucárias; Por filho acima de 12 anos de idade - 8,0 hectares de campo limpo; Por filha acima de 17 anos de idade - 4 hectares de campo limpo. A pós feita a distribuição existiram 2507 parcelas de campo limpo e florestas, entre lotes residenciais. A propriedade 
média de cada família ficou em 45 hectares. A distribuição das parcelas foi realizada através de sorteio. Desse modo, os colonos não podiam escolher suas terras. Aconteceu, então, que um residente no Norte de uma aldeia ganhou um lote no extremo Sul da respectiva área, aumentando-se a distância a ser percorrida para o trabalho e para os transportes. Ou um criador por vocação ficou com terras mãos adequadas para a agricultura mecanizada e vice-versa. Esse fato e o excesso de parcelamento, ainda não superado, tem causado muitas dificuldades. (ELFES, 1973, p. 2012)

A Cooperativa recebeu grandes financiamentos subsidiados pelo governo Federal e pelo Banco do Brasil e do Governo Federal da Alemanha, que repassavam aos colonos em forma de empréstimos a juros mais baixos que o praticado no mercado financeiro, fornecia-se ainda os insumos, sementes e aluguel de maquinas agrícolas. Portanto, o sistema deixava o colono dependente e subordinado ao interesse do sistema cooperativo. Evidente que essa lógica garantia um melhor controle da produção, acompanhamento técnico e a produção em larga escala. O sucesso de todas as etapas de produção permitiria ao colono acesso a distribuição de lucros, já que era sócio da cooperativa. Era o novo mundo chegando definitivamente o campo no Paraná (ELFES, 1973, p. 92-93).

Apesar do projeto de colonização contar com auxílio econômico, político e técnico o mesmo apresentou problemas sérios como crise financeira, dificuldades técnicas, crise de confiança e falta de orientação.

O orçamento do projeto organizado pela sociedade "Ajuda Suíça" apresentou-se insuficiente já em 1952. Como o projeto foi pensado e organizado em terras fictícias, onde a fertilidade e os problemas de pragas e produtividade seriam perfeitamente solucionáveis.

Na prática demonstrou-se totalmente incorreta, ocasionando uma série de problemas de produção e quebra de safra, pela acidez do solo que exigiu grandes investimentos de adubos e fertilizantes encarecendo o custo de produção, que não estavam previstos no projeto original. Foi o que ocorreu no primeiro ano de cultivo, o solo não reagiu como previsto, faltando adubo e maquinas adequadas.

Outra situação diagnosticada tardiamente foram observar pela prática do trabalho com o campo, em que o maquinário agrícola importado para tipos de solos específicos alemães, mostraram-se ineficientes obrigando os colonos a recorrerem a equipamentos de tração animal. Até os arados de tração animal trazidos da Europa apresentaram problemas, pois eram conduzidos por grandes cavalos de raça europeia e não para os cavalos leves encontrados nas terras guarapuavanas.

O mesmo raciocínio ocorreu com as máquinas industriais importadas da Alemanha, que para o tipo de matéria-prima brasileira não foi utilizável de forma eficiente, este fato ocorreu com máquinas de serrarias, 
de beneficiamento de arroz e de moinho de trigo. Esses investimentos pensados sem conhecimento do local onde iriam produzir demonstraram-se um fracasso técnico e de grande prejuízo econômico, fruto da falta de experiência dos planejadores do projeto e dos colonos. Isso provocou um grande déficit nas previsões orçamentárias.

A perda de confiança no projeto foi a primeira consequência dos erros técnicos, que somaram ao atraso do parcelamento e a consequente coletivização dos trabalhos extra agrícolas, provocando o descontentamento dos artesãos e operários que desejam autonomia econômica. Além dos resultados agrícolas, a distribuição das terras sem a utilização de critérios utilitários como já apresentado, conduzira um desânimo com o projeto levando 60 famílias a saírem do projeto entre 1953/54, retornando a Alemanha.

Faltaram aos dirigentes da cooperativa na fase inicial, um conhecimento da realidade econômica brasileira, apesar de gozarem de confiança tanto do grupo financiador Suíço como do Banco do Brasil. Outro fator complicador foi a falta de domínio da língua portuguesa e a consequente compreensão da nossa cultura levando a tomarem julgamentos equivocados e atrasos em decisões, que levaram o Banco do Brasil em 1954, a instituir um interventor na colônia como forma de garantir os investimentos ali aportados.

Aliados a toda a situação descrita acima ainda faltaram orientações básicas aos colonos, acostumados com um tipo produção e de solo na Alemanha, que não precisava de adubo pelas terras férteis. Na nova colônia foram obrigados durante anos a fazerem a correção do solo, que obrigou a usurem muito adubo e fertilizantes.

Como não estavam acostumados com a política agrícola brasileira que não definia preços mínimos para o trigo, levou a colônia durante 15 anos vacilante para definir sua linha de produção. Levando baixos investimentos e baixos lucros (ELFES, 1973, p. 90).

Essa visão de mudança dos campos foi exposta por Munhoz da Rocha (ELFES, 1971, p. 7) "Só benefícios houve na instalação de Entre Rios que consolidou, em bons termos, a valorização de nossos campos gerais, atingindo a todos, inclusive aos brasileiros que, notavelmente sensíveis ao novo e ao melhor, adotaram as novas técnicas de utilização da terra". 
Figura 1: Mecanização da Colônia de Entre Rios, 1952.

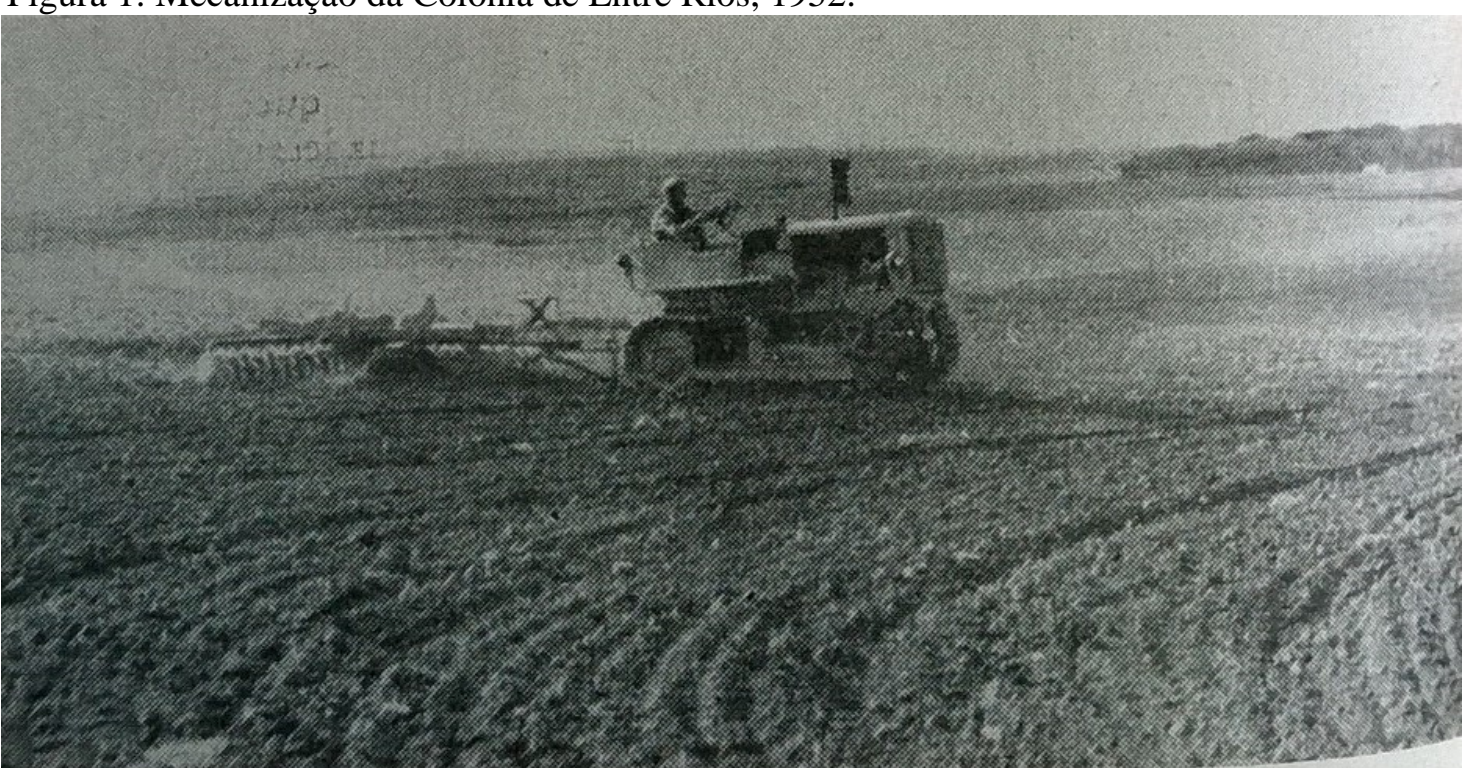

Fonte: Guia Globo de Exportação e Importação do Paraná, 1953, p.100

Essa visão de mudança dos campos foi exposta por Munhoz da Rocha (ELFES, 1971, p. 7) "Só benefícios houve na instalação de Entre Rios que consolidou, em bons termos, a valorização de nossos campos gerais, atingindo a todos, inclusive aos brasileiros que, notavelmente sensíveis ao novo e ao melhor, adotaram as novas técnicas de utilização da terra".

A figura 2, apresenta a visita do governador paranaense na Colônia de Entre Rios, o apoio governamental ao processo de colonização dos alemães Suábios de Entre Rios, aos quais depositavam-se a capacidade de transformar os campos de Guarapuava e Pinhão, servindo de estímulo e inspiração aos demais agricultores vizinhos, a colônia para o acadêmico Munhoz da Rocha era na verdade um experimento, um laboratório de novas práticas agropecuárias e industriais. 
Figura 2: Visita do governador Bento Munhoz da Rocha na colônia de Entre Rios, 1952.

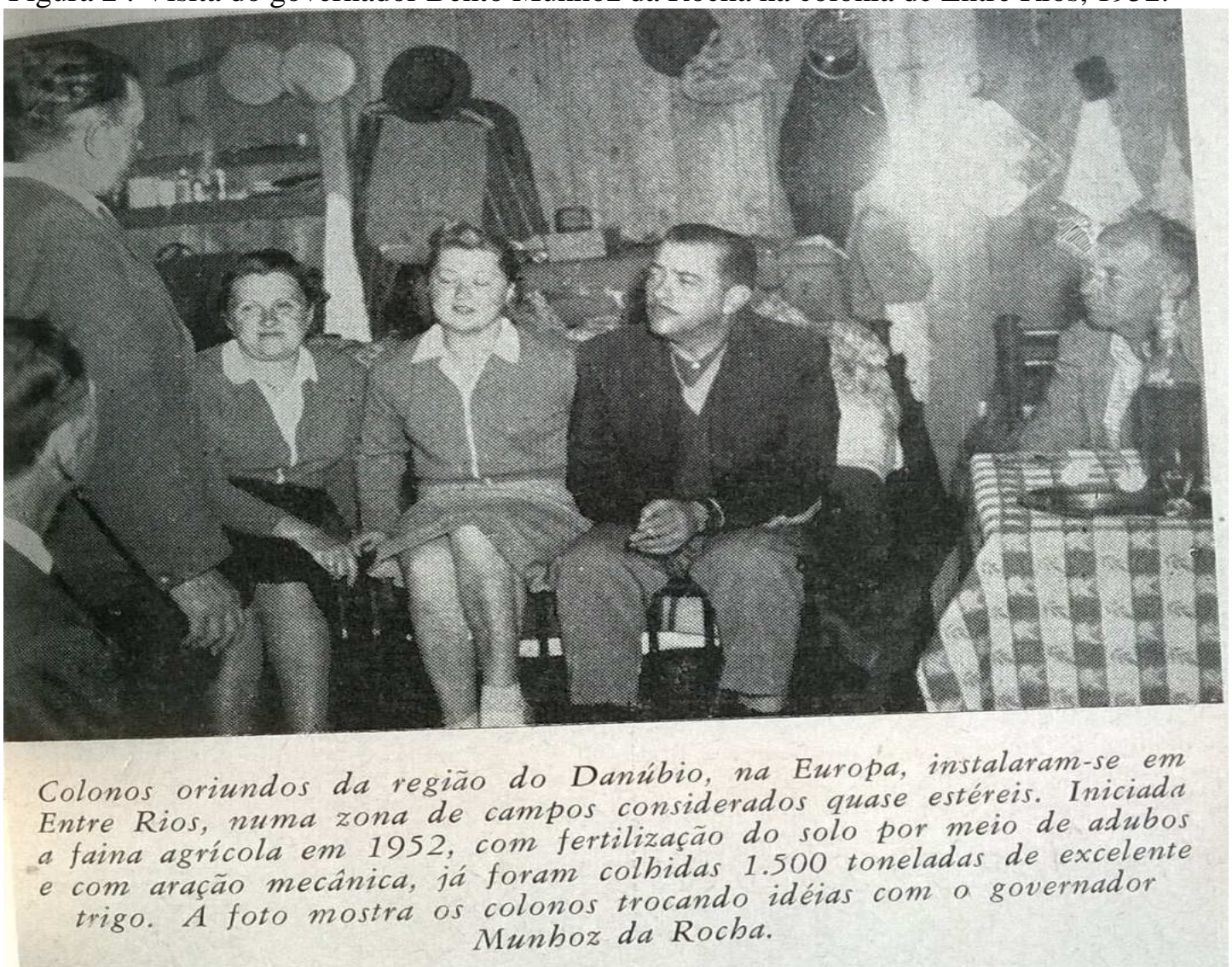

Fonte: Guia Globo de Exportação e Importação do Paraná, 1953, p.103

Uma das respostas aos problemas enfrentados foi a expansão da área da colônia, com a compra de terras próximas da colônia original, como atender as reclamações de vários colonos que reclamavam do processo de distribuição das terras. No início dos anos de 70, compraram a posse da fazenda Fundão, no município do Pinhão, atualmente Reserva do Iguaçu, do ex-delegado do Pinhão Oscar Pacheco. Quase que imediatamente iniciaram o processo de regularização fundiária da terra, mas a fazenda centenária pertenceu a Balbina Siqueira, que entregou uma grande área desta aos seus ex-escravos. Seus descendentes iniciaram uma grande luta jurídica e política para retornar as terras da fazenda Fundão denominada com Invernada Paiol das Telhas. A guerra judicial ocorre até os dias atuais, pois o governo Federal decretou pelo Incra, a fazenda como área Quilombola, que luta pela desapropriação.

Do ponto de vista econômico e de aproveitamento da terra e suas potencialidades é inegável o desenvolvimento apresentado pela colônia de Entre Rios e sua Cooperativa Agrária. Podemos questionar o processo de expansão que passou a Cooperativa Agrária que passou a adquirir uma grande quantidade de terras em toda região de Guarapuava, Pinhão, Reserva do Iguaçu e Candói, quando anteriormente era restrita 
a Guarapuava. Então, se a chegada dos colonos representou uma democratização de acesso a terra, pois 7 proprietários controlavam toda área da colônia, verificamos hoje uma concentração da terra em mãos da cooperativa ou associados, criando novamente uma nova oligarquia. Outra situação foi a forma que participou do processo de expropriação da fazenda Invernada Paiol da Telhas, hoje reconhecido como área Quilombola.

\section{A COLONIA CASTROLANDA: CONSIDERAÇÕES SOBRE A OCUPAÇÃO}

O ambiente do pós-guerra na Europa foi desalentador, cidades destruídas, campos minados, famílias destroçadas e economia em caos. Nesse cenário desalentador que representações diplomáticas de vários países europeus buscam países dispostos a receber milhares de trabalhadores do campo e da cidade. O Brasil apresenta-se como desses destinos pela grande oferta de terras disponíveis e pelas oportunidades que um país em construção poderia oferecer.

Nesse cenário foram realizadas inúmeras reuniões entre 1947-50 entre consulados e representações diplomáticas da Holanda e Brasil, que culminou com instalação da colônia "Holambra", no interior do Estado de São Paulo. Foi a primeira experiência colonial holandesa no país (ELFES, 1968, p. 47).

Em 1950, chegou ao país uma comissão de estudos da Holanda com objetivo de encontrar terras para criação de uma nova colônia holandesa, depois de verificar terras no Rio Grande do Sul deu preferência pelas terras no município de Castro, que eram campos planos que facilitava a mecanização e de clima favorável. Essa decisão também ocorreu pelo fato do interesse apresentado pelo governo do Paraná, que deu todo suporte e garantias para a instalação da colônia (ELFES, 1968).

O governo Paranaense tinha um projeto em curso de Modernização da economia paranaense, e dinamizar a agricultura e pecuária eram objetivos centrais no projeto. Entendiam que a mudança dos paradigmas da agricultura de subsistência, para uma agricultura comercial e voltada aos interesses do mercado externo, passaria pelo domínio de novas técnicas agropecuária e da mecanização. Para tanto, somente trabalhadores acostumados com tais técnicas estariam preparados, que na visão dos representantes do governo seriam os imigrantes europeus.

Verificamos que houve uma organização e articulação que possibilitaram uma verdadeira mudança, que trouxe melhores condições aos novos colonos recém-chegados ao Brasil, situação 
bem diferente da maioria dos núcleos coloniais estabelecidos desde o século XIX, em todo território brasileiro. As terras foram compradas do Governo Brasileiro, anteriormente a 1880, as terras pertenciam a fazenda Capão Alto, que tinha um total de 70 mil hectares, que no decorrer do tempo foram vendidas parceladamente. Inicialmente foram adquiridos 7.000 mil hectares. Atualmente ocupa um total de 42 mil hectares, com áreas individuais de 40 até 200 hectares.

Essa colonização foi planejada, o que a tornou diferente quando pensamos em imigração com famílias que chegam com somente suas roupas, esperanças e pouco dinheiro, nesse caso específico ocorreu na verdade uma grande mudança, isso mesmo. As famílias que emigraram para o Brasil, tiveram toda sua mobília, utensílios, gado leiteiro, maquinários transportados da Holanda até a nova colônia.

A mudança nestas condições foi possível porque, ainda, na Europa foi a criada a uma cooperativa que teve como objetivos a mudança e a compra de terras. O Diário Oficial dos Países Baixos na sexta-feira, 28 de setembro de 1951, n 188 , saiu com o seguinte suplemento:

\footnotetext{
Coöperatieve Vereniging Groepsemigratie Brazilië G. A. (Sociedade Cooperativa de emigração em Grupo Brasil G. A.), em Hoogeveen. Hoje, aos vinte dias do mês de julho do ano de mil novecentos e cinquenta e um, compareceram perante mim, Eeltje Visser, tabelião local deste município de Hoogeveen, na presença das testemunhas adiante nomeadas, os senhores: 1: Geert Leffers, agricultor, dominiciliado Kamerlingswijk 16, Zwartemeer, município de Emmen. Artigo 1; A sociedade tem nome: Sociedade Cooperativa de Emigração em Grupo Brasil G. A.; A duração da sociedade é por tempo indeterminado. Artigo 2: o objetivo da Sociedade é promover a possibilidade de imigração de holandeses para o Brasil e, no sentido mais amplo, defender os interesses doa associados relativos a tal emigração. Artigo 3: 1. A Sociedade visa alcançar este objetivo através da: a) organização da exportação dos bens dos associados na forma de materiais de produção e capital até o valor máximo permitido pelo governo da Holanda. B) a compra ou aquisição por outra forma, direta ou indiretamente, de terras no Brasil (KIERS-POT, C.H.L. 2001, p. 115).
}

Fazem parte da Cooperativa atualmente 518 sócios, sendo um terço de origem holandesa. A Cooperativa tem 408 funcionários, nas fazendas trabalham cerca de 4 empregados em média, o que significa uma renda para mais de 2000 famílias. Muito diferente de anteriormente quando todas as terras formavam a fazenda Capão Alto de propriedade de Bonifácio José Batista, que havia recebido o título de posse de D. Pedro II, em 1886.

Esse tipo de movimento trouxe repercussões econômicas e sociais no campo paranaense, provocando a transição de uma agricultura de subsistência, para uma especializada, com rotação de terras e culturas, em combinação com a pecuária leiteira e na criação de suínos 
A força motrix que levou a esse processo de mudança, foi a busca de terras pois na Europa não haviam terras disponíveis o que comprometeria as novas gerações, complicada pelo pós-guerra, a saída era buscar fora da Europa e o Brasil apresentava-se com terras disponíveis e um governo receptivo a chegada de imigrantes.

\section{CONSIDERAÇÕES FINAIS}

O processo de formação das colônias aqui explicitadas, representaram a adoção de um novo formato com características como o planejamento e a organização na chegada desses imigrantes, garantindo melhores condições de acesso e permanência na terra, com programas de financiamentos e orientação técnica.

Outra situação percebida que a maioria dos imigrantes eram alfabetizados e tiveram acesso a mínimo de educação formal, por isso valorizavam a educação, pois em todas as colônias foi praticamente automático a implantação da escola primária e técnica, garantindo uma nova geração preparada para novos desafios. A cultura europeia que trouxeram na bagagem de centenas de anos de aprimoramento de técnicas agropecuárias ajudou muito no processo de adaptação.

A religião ajudou na unidade dos colonos nos muitos mais complicados, pois pregavam a simplicidade, o trabalho, o respeito as normas e regras, características igrejas protestantes, principalmente a influência Calvinista e Luterana, encaravam o sistema de produção o cooperativismo, as relações econômicas e o lucro com naturalidade de centenas de anos de convivência destas na Europa.

Podemos criticar o governo brasileiro por não oferecer as mesmas condições aos pequenos agricultores brasileiros, que poderiam com investimentos educacionais e técnicos exercerem o mesmo papel realizados pelos colonos imigrantes. Esse fenômeno acabou contribuindo regionalmente para o aumento do preconceito contra o pequeno agricultor, caboclo faxinalense, o posseiro e os assentados da reforma agrária, que vivem de uma agricultura de subsistência, com pouco acesso a financiamentos, maquinário, educação de baixa qualidade e além da falta de qualificação e orientação técnica que são invariavelmente comparados de maneira imprópria com os colonos imigrantes, sem que a população conheça a história envolvida neste processo da formação das colônias. 
O modo de vida do agricultor tradicional da região que viviam em faxinais, o caboclo tem suas relações econômicas percebidas como rebeldes ao olhar da burguesia regional e estadual como afirma Thompson (1998, p. 19):

Uma cultura tradicional que é, ao mesmo tempo, rebelde. A cultura conservadora da plebe quase sempre resiste em nome do costume, às racionalizações e inovações da economia (tais como os cercamentos, a disciplina de trabalho, os "livres" mercados de cereais) que os governantes, os comerciantes ou empregadores querem impor. A inovação é mais evidente na camada superior da sociedade, mas como ela não é um processo tecnológico/social neutro e sem normas (modernização e racionalização), mas sim a inovação do processo capitalista é quase sempre experimentada pela plebe como uma exploração, a expropriação de direitos de uso e costumes.

O caboclo é encarado pela burguesia regional como atrasado e que a agricultura que produz não traz riqueza e prosperidade para a região por ser voltada a subsistência e ao mercado local, não gerando a riqueza desejada pela burguesia.

\section{REFERÊNCIAS}

BALHANA, Altiva Pilatti e MACHADO, Brasil Pinheiro (Org). Campos Gerais: Estruturas Agrárias. Curitiba: UFPR, 1968.

BOURDIEU, Pierre. A economia das Trocas Simbólicas. São Paulo: Perspectiva, 2007.

EIDAM, Rodrigo. A Análise da formação da consciência Histórica tomando como estudo de caso duas colônias alemãs nos Campos Gerais - $P R$, acessível no site: www.brasilalemanha.com.br/novo site/noticia/estudo-cientifico-sobre-imigracao-alema-por-rodrigo-eidam/4410, acessado dia 25/04/2016.

ELFES, Alberto. Campos Gerais: Estudos da Colonização. Curitiba: INCRA, 1973. Suábios do Danúbio. Curitiba: Edição do autor, 1971.

EWERT, Grasiele Kapp; KARAS, Samanta Hass; LAMP, Roberto Edgar. A Imigração Menonita na Colônia Witmarsum: A formação da colônia a partir de 1951. In: Revista Ateliê de História. Ponta Grossa: UEPG, 2013. 
GREGORY, Valdir. Os Eurobrasileiros e espaço colonial: Migrações no Oeste do Paraná (1940-1970). Cascavel: EDUNIOESTE, 2008.

MARTINS, Jose de Souza. Cativeiro da Terra. 9 ed. São Paulo: Contexto, 2015.

MARX, Karl. O Capital Crítica da Economia Política. Vol. 1: O Processo de Produção de Capital. São Paulo: Editora Nova Cultural, 1996.

PORTO, Liliana; SALLES, Jefferson de Oliveira; MARQUES, Maria dos Santos (Org). Memórias dos Povos do Campo no Paraná Centro-Sul.Curitiba: ITCG, 2013.

RAMOS, Rene Wagner. O conflito entre os Caboclos e a Madeireira Zattar, no Município do Pinhão - PR. IN: Congresso Internacional de História 2015. Passo Fundo, UPF, 2015.

KIERS-POT, C.H. Castrolanda 50 anos 1951-2001. Castro: Kugler Artes Gráficas, 2001.

THOMPSON, E. P. Costumes em comum: estudos sobre a cultura popular tradicional. São Paulo: Cia. das Letras, 1998.

WACHOWICZ. Ruy. História do Paraná. 9 ed. Curitiba: Imprensa Oficial do Paraná, 2001.

STEIN,Marcos Nestor. A colônia de Entre Rios no município de Guarapuava. VITECK, Harto (Org). Imigração Alemã no Paraná 180 anos - 1829-2009. Marechal Cândido Rondon: Editora Germânica, 2012. 


\title{
Colonies Castrolanda, Witmarsum e Entre Rios and agroindustrialization field in Paraná
}

\begin{abstract}
The article discusses the deployment process, consolidation and the current success of the colonies of Castrolanda Castro (Cooperativa Castrolanda) Witmarsum in Palmeira ( Cooperativa Witmarsum ) and Entre Rios in Guarapuava ( Agrária Cooperativa), which led the three major companies in Parana with R $\$ 4.5$ billion revenues in 2015 . We will analyze the participation of the government of Bento Munhoz da Rocha, in the implementation of the colonies in 1951, identifying the strategies adopted and the justification of speech to the state 's commitment in this process. The Modernization Project of the field, was premised on the transformation of the production model and its association to the industrial process as a way to add value to the final product would be exported.
\end{abstract}

Key-words: Cologne; Modernization. Agro-industrialization. Bento Munhoz da Rocha. Cooperativa. 